
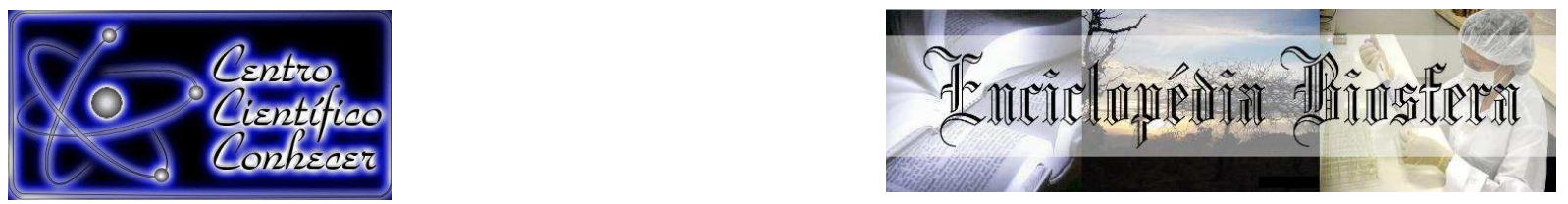

\title{
MORFOMETRIA DA SUB-BACIA DO RIO MOJU NA FLONA DO TAPAJÓS, OESTE DO PARÁ
}

\footnotetext{
Leonardo Sousa dos Santos ${ }^{1}$, Lucieta Guerreiro Martorano ${ }^{2}$, Sarah Suely Alves Batalha $^{3}$, Altem Nascimento Pontes ${ }^{4}$ Nicola Saverio Holanda Tancredi ${ }^{5}$

${ }^{1}$ Mestre em Ciências Ambientais, Universidade do Estado do Pará (UEPA), Brasil. email: leonardocbmpa@yahoo.com.br

${ }^{2}$ Pesquisadora da Empresa Brasileira de Pesquisa Agropecuária (EMBRAPA) Amazônia Oriental, Brasil.

${ }^{3}$ Doutoranda do Programa de Pós-graduação em Sociedade, Natureza e

Desenvolvimento, Universidade Federal do Oeste do Pará (UFOPA), Brasil.

${ }^{4}$ Professor e Pesquisador do Programa de Mestrado em Ciências Ambientais, Universidade do Estado do Pará (UEPA), Brasil.

${ }^{5}$ Doutor em Sociedade, Natureza e Desenvolvimento. Universidade Federal do Oeste do Pará (UFOPA), Brasil.
}
Recebido em: 03/10/2016 - Aprovado em: 21/11/2016 - Publicado em: 05/12/2016 DOI: 10.18677/EnciBio_2016B_071

\begin{abstract}
RESUMO
O objetivo deste trabalho foi caracterizar a morfometria da sub-bacia hidrográfica do rio Moju (SBHRM) que integra a bacia do rio Amazonas, importante via de escoamento do pólo de grãos no oeste paraense. A partir do Modelo Digital de Elevação (MDE), extraído de imagens orbitais do sensor Advanced Spaceborne Thermal Emission and Reflection Radiometer (ASTER), satélite TERRA/NOAA, fez-se o recorte na Área de Entorno para obtenção de dados de MDE. As análises foram realizadas no Sistema de Informação Geográfica QGis 2.8, aplicando a ferramenta Terrain Analysis Using Digital Elevation Models (TauDEM). Os resultados evidenciaram que $77 \%$ dos canais da SBHRM são de $1^{\text {a }}$ ordem, totalizando um desdobramento do sistema de drenagem com 1.233 canais que correspondem a 2.907,87 km de curso d'água. O rio Moju possui categoria hierárquica de $6^{\underline{a}}$ ordem, evidenciando sua característica ramificada de natureza dendrítica, semelhante a uma árvore. A morfometria da sub-bacia do rio Moju permite caracterizá-la de acordo com o coeficiente de capacidade $(1,57)$; fator forma alongada $(0,16)$ e tipo de drenagem dendrítica como de baixa suscetibilidade a enchente e acúmulo de água em eventos de chuvas intensas na bacia doAmazonas. Cerca de $60 \%$ da sub-bacia do rio Moju possui elevada e média iluminação. Conclui-se que as características morfométricas da sub-bacia podem subsidiar o gerenciamento e outorgas de água, canais prioritários para abastecimento hídrico e principais vias de contaminação de água pelo processo antrópico.
\end{abstract}

PALAVRAS-CHAVE: Análise espacial. Delimitação Automática de Bacias. Recursos hídricos. SRTM 


\title{
MORPHOMETRY OF THE SUB-BASIN OF THE MOJU RIVER IN THE TAPAJÓS NATIONAL FOREST IN WESTERN PARÁ
}

\begin{abstract}
This study aimed to characterize the morphometry of the Moju River sub-basin (MRSB) that is part of the Amazonas River basin, an important shipping lane of grains in the west of the state of Pará, Brazil. From the Digital Elevation Model (DEM), extracted from orbital images from the Advanced Spaceborne Thermal Emission and Reflection Radiometer (ASTER) sensor of the TERRA/NOAA satellite, the area of interest was sampled to obtain the DEM data. The analyses were carried out in the Geographic Information System QGis 2.8 by applying the Terrain Analysis Using Digital Elevation Models (TauDEM) tool. The results showed that $77 \%$ of the canals in the MRB are of the 1st order, for a total drainage system with 1,233 canals that correspond to $2,907.87 \mathrm{~km}$ of water courses. The Moju river has a hierarchical category of the 6th order, which shows its ramified character of a dendritic nature, similar to a tree. The morphometry of the MRB allows characterizing it according to the capacity coefficient (1.57), elongated form factor $(0,16)$, and dendritic drainage type with low susceptibility to floods or water accumulation during intense rainfall in the Amazonas Basin. About $60 \%$ of the Moju River sub-basin has medium to high illumination. It is concluded that the morphometric characteristics of the sub-basin may lay basis for the management and granting of water resources, priority canals for water supply, and main routes of water contamination through anthropic process.
\end{abstract}

KEYWORDS: Water resources. SRTM. Automatic basin delimitation. Spatial analysis.

\section{INTRODUÇÃO}

As análises de dados obtidos com sensores remotos têm permitido a obtenção de informações referentes a objetos na superfície terrestre, os quais permitem ampliar as investigações em diversas áreas do conhecimento científico (JENSEN, 2009). OLIVEIRA et al. (2010) ressaltaram que o uso de dados orbitais de padrões na superfície terrestre está intimamente relacionado aos suportes computacionais e avanços geotecnológicos.

O interesse em ampliar as investigações das propriedades e suas relações posicionais de eventos registrados a distância vem permitindo melhorar as escalas de detalhes e, ainda a representação da realidade ambiental (SALES, 2004). Aplicações usando dados de Modelo Digital de Elevação (MDE) a partir de imagens orbitais do sensor "Advanced Spaceborne Thermal Emission and Reflection Radiometer" (ASTER/TERRA/NOAA) têm também auxiliado na delimitação, principalmente de bacias hidrográficas, rede de drenagem, hierarquia de canais, direção de fluxo, dentre outros (TOMAZONI et al., 2011).

As aplicações de técnicas de geoprocessamento têm subsidiado, sobretudo, o planejamento, a gestão e a conscientização do manejo e uso dos recursos hídricos em bacias hidrográficas (RIBEIRO et al., 2015). PEREIRA et al. (2015), afirmam que a partir do uso de dados MDE pode-se avaliar o porte da bacia hidrográfica, hierarquias de canais, índices de relevo e densidade de drenagem da bacia hidrográfica, como, por exwmplo, a do rio Peixe-Boi, no nordeste do estado do Pará, onde através de MDE OLIVEIRA et al. (2015) avaliou as características morfométricas da sub-bacia 
hidrográfica de Ribeirão São Bartolomeu, no estado do Espírito Santo, além de identificar o tipo de ramificação dendrítica e áreas de risco de enchentes.

BIELENKI JUNIOR \& ARBASSA (2012) explicam que a política Nacional de Recursos Hídricos, baseada na Lei Federal no 9.433 de 1997 prevê a utilização de geotecnologias na geração de dados hidrográficos (bacias, trechos de drenagens, curvas de níveis, entre outros). Essas análises visam o gerenciamento de recursos hídricos dentro da sua célula básica que é a bacia hidrográfica, permitindo estudos capazes de prognosticar situações futuras com o apoio de modelagem espaçotemporal.

O entendimento de variáveis biofísicas em bacias hidrográficas, com o uso de informações remotas, permitem subsidiar o gerenciamento e outorgas do direito de uso prioritários da água, irrigação, análises de potencial hidroelétrico, assim como o controle de enchentes, potencial de abastecimento hídrico. Outros aspectos decorrente da utilização de dados orbitais são estudos sobre vulnerabilidade de bacias a processo erosivo, dinâmica de transporte de sedimentos, bem como informações sobre as principais vias de contaminação hídrica, locais propícios ao uso recreativo da água, entre outras aplicações diretas (SANTOS et al., 2016). O objetivo deste trabalho foi realizar o estudo morfométrico da sub-bacia hidrográfica do rio Moju (SBHRM) que integra a bacia do rio Amazonas em gestão hídrica no contexto da Floresta Nacional (FLONA) do Tapajós e seu entorno.

\section{MATERIAL E MÉTODOS}

\section{Área de Estudo}

A área de estudo corresponde a sub-bacia hidrográfica do rio Moju (SBHRM) pertencente a bacia do rio Curuá-Una, localizada na Floresta Nacional do Tapajós (FNT) ou FLONA Tapajós, no oeste do Estado do Pará, entre os paralelos $2^{\circ} 28^{\prime}$ 52,25"

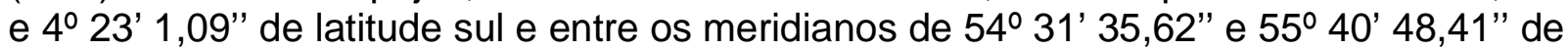
longitude oeste. Mais de $60 \%$ da SBHRM pertence a FLONA do Tapajos, que tem uma área total de $5.273,69 \mathrm{~km}^{2}$. A FNT é uma Unidade de Conservação de Uso Sustentável criada pelo Decreto no 73.684 de 19 fevereiro de 1974.

A Flona do Tapajós está sob a jurisdição do Instituto Chico Mendes de Conservação e Biodiversidade (ICMBio) e integrada ao sistema nacional de áreas protegidas. O ICMBio possui sete Bases de fiscalização ao longo da da rodovia Cuiabá-Santarém (BR-163). A FNT limita-se, ao norte com o km 50 da BR-163; ao sul, com a Rodovia Transamazônica e os rios Cupari e Cuparitinga ou Santa Cruz; a leste, com a rodovia BR-163; e a oeste com o rio Tapajós. Na Figura 1 fez-se a identificação da área da FNT, bem como o destaque para a SBHRM, onde foram concentradas as avaliações morfométricas. 

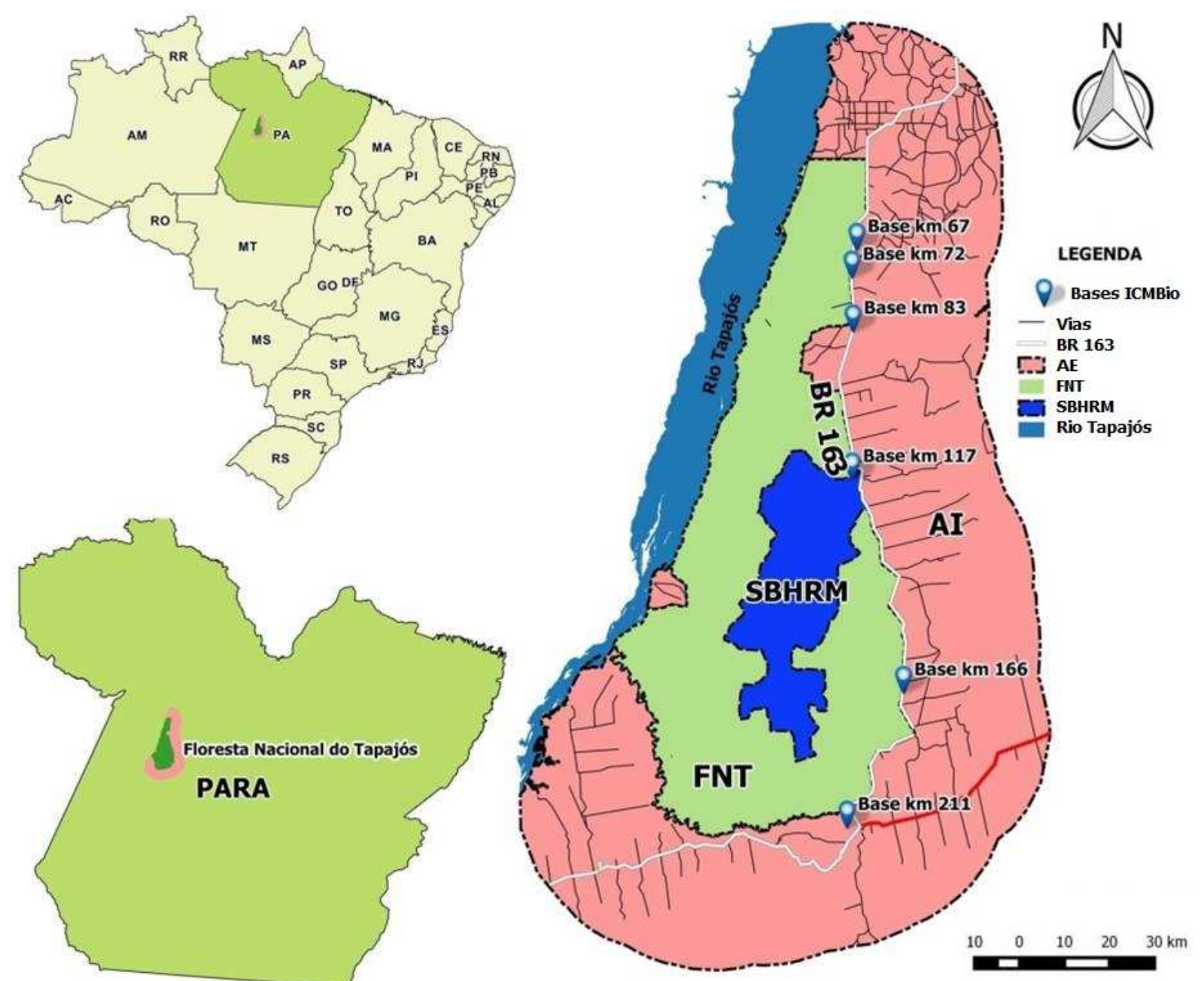

FIGURA 1. Localização da SBHRM na FLONA do Tapajós e seu entorno, PA.

Para o referido estudo foi construída uma base de dados georreferenciados, com planos de informações, em escala de 1:30.000. Nessa etapa, utilizou-se o sistema de informação geográfica (SIG) QGis 2.8, versão Wien, licenciado pela General Public License (GNU). Na segunda etapa, foi originado um mosaico das cenas S03W056, S04W056, S03W055 e S04W055 a partir das imagens orbitais do sensor ASTER, do satélite TERRA/NOAA, disponibilizadas gratuitamente pelo governo norte americano através da "United States Geological Survey" (USGS), http://landsat.usgs.gov/, com resolução espacial de 60 metros.

$\mathrm{Na}$ terceira etapa, através do MDE fez-se a extração da sub-bacia do rio Moju, bem como sua rede de drenagem. Utilizou-se o conjunto de ferramentas do complemento "Terrain Analysis Using Digital Elevation Models" (TauDEM), sobre a plataforma QGis 2.8, que possibilita a análise de terreno, extração de informações hidrológicas da topografia, dentre outros (BOSSLE, 2015), conforme Figura 2. 


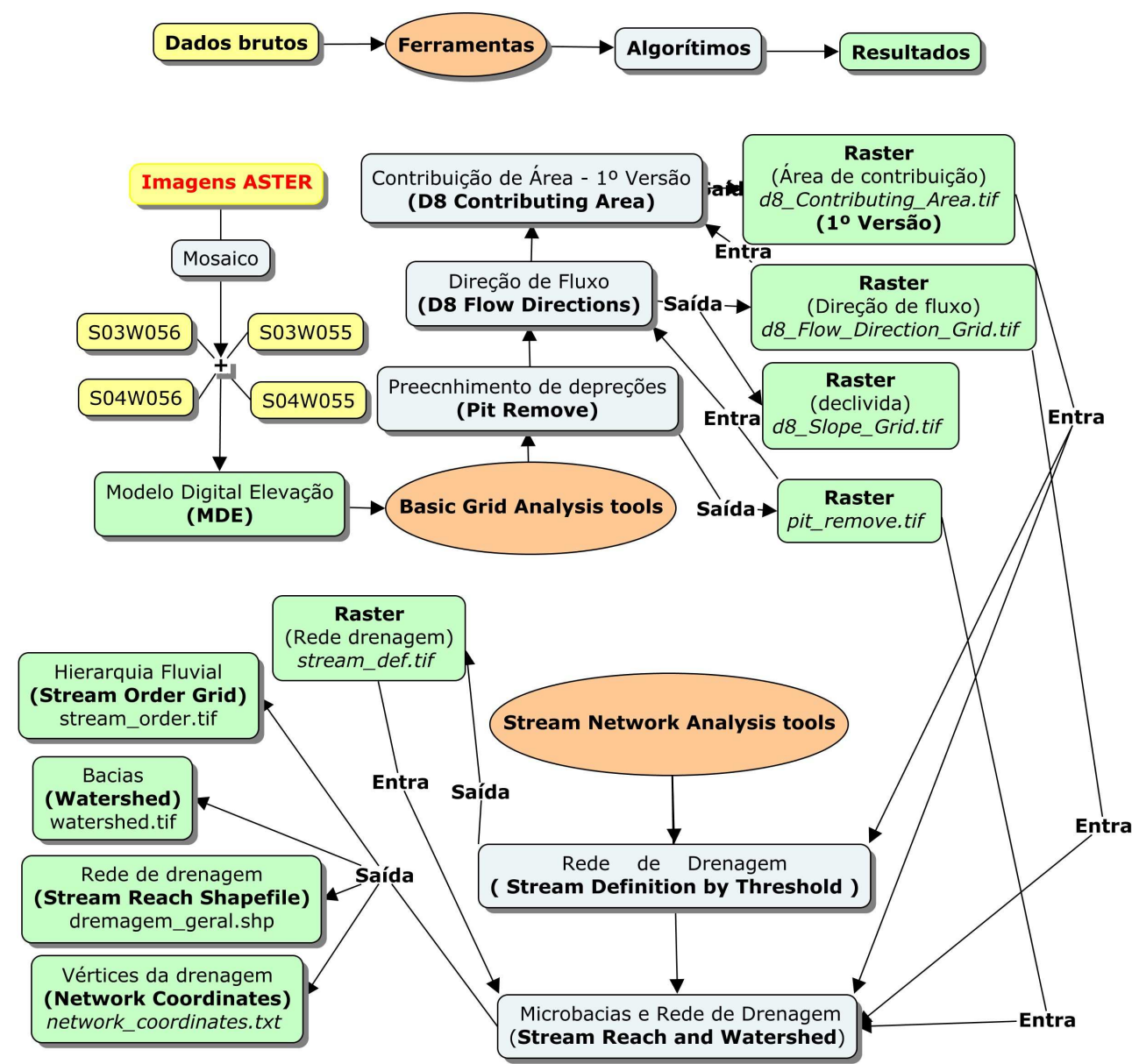

FIGURA 2. Diagrama metodológico de geração do limite que delimita a bacia hidrográfica com TauDEM.

$\mathrm{Na}$ quarta etapa, elaborou-se mapa de exposição solar do terreno, iniciando a contagem a partir do norte $\left(0^{\circ}\right)$ e avançando no sentido anti-horário através da simulação do nível de luz (ou sombra) refletida pelo relevo ao ser iluminado pelo sol. A classificação de baixa, média e alta exposição solar, tomou-se como referência os pontos cardeais, de acordo com OLIVEIRA et al. (2010).

Por fim, realizou-se trabalho de campo no período de 5 a 11 de janeiro de 2016, nos horários de 10 às 15 onde foram levantados dados para confirmar informações obtidas nas análises de dados dos sensores orbitais. Fez-se os registros fotográficos para reforçar as informações geoambiental referentes à SBHRM, obtendo-se novos dados espaciais e cartográficos, além de registros de aspectos fisiográficos, recursos biofísicos, sedimentos nos corpos hídricos, desflorestamento de vegetação ciliar na ponte sobre o rio Moju, próximo a Base do km 117 do ICMBio na BR 163, entre outros.

Ainda nesta etapa, utilizou-se pranchetas para anotação e o receptores de Sistema de Posicionamento Global (GPS) modelo "Garmim Etrex 30" para levantamento de campo e aquisições de coordenadas geográficas de nascentes, igarapés, dentre outros. O trabalho de campo permitiu a consolidação das etapas metodológicas durante as análises de geoprocessamento, em laboratório. 


\section{Avaliações referentes à morfometria da sub-bacia hidrográfica do rio Moju (SBHRM)}

Dividiu-se o estudo morfométrico em duas categorias, conforme HORTON (1945), VILLELA \& MATTOS (1975) e CHRISTOFOLETTI (1981), incluindo aspectos lineares (identificação da hierarquia fluvial, relação de bifurcação, relação entre o comprimento médio dos canais por hierarquia) e aspectos areais (forma e determinação da densidade de drenagem, densidade hidrográfica, coeficiente de manutenção, relação de relevo e declividade). Com os resultados destes cálculos, pode-se fazer um diagnóstico sobre os indicadores hídricos das subáreas, cujo resumo encontra-se na Quadro 1.

QUADRO 1. Resumo do processo metodológico aplicado na análise linear e areal da SBHRM.

\begin{tabular}{|c|c|c|c|c|}
\hline Item & Análise & Equação & Definição & Significado \\
\hline Qc & $\begin{array}{l}\text { Quantidade de } \\
\text { canais }\end{array}$ & --- & ---- & $\begin{array}{l}\text { Corresponde a somatório } \\
\text { de todos os canais de } \\
\text { drenagem }\end{array}$ \\
\hline$L p$ & $\begin{array}{l}\text { Comprimento do } \\
\text { canal principal }\end{array}$ & --- & ---- & $\begin{array}{l}\text { Refere-se à extensão do } \\
\text { canal principal da } \\
\text { drenagem; }\end{array}$ \\
\hline$L t$ & $\begin{array}{l}\text { Comprimento total } \\
\text { do canal }\end{array}$ & --- & --- & $\begin{array}{l}\text { Refere-se à extensão do } \\
\text { total de uma ordem de } \\
\text { drenagem; }\end{array}$ \\
\hline Lmd & $\begin{array}{l}\text { Comprimento } \\
\text { médio dos canais }\end{array}$ & --- & --- & $\begin{array}{l}\text { Razão entre a somatória } \\
\text { de todos os canais de } \\
\text { drenagem e a somatória } \\
\text { de todas as extensões de } \\
\text { canais. }\end{array}$ \\
\hline$H c$ & $\begin{array}{l}\text { A hierarquia dos } \\
\text { canais }\end{array}$ & --- & ---- & $\begin{array}{l}\text { É medida do grau de } \\
\text { ramificação dos canais } \\
\text { de drenagem. }\end{array}$ \\
\hline$R b$ & $\begin{array}{l}\text { Relação } \\
\text { bifurcação }\end{array}$ & $R b=\frac{N w}{N w+1}$ & $\begin{array}{l}\text { Nw: número } \\
\text { total de canais; } \\
\text { Nw+1: número } \\
\text { total de canais } \\
\text { de } \\
\text { superior. }\end{array}$ & $\begin{array}{l}\text { É a razão entre o número } \\
\text { total de canais de certa } \\
\text { ordem e o número total } \\
\text { de canais de ordem } \\
\text { imediatamente superior. }\end{array}$ \\
\hline$R L m$ & $\begin{array}{l}\text { Relação entre o } \\
\text { comprimento } \\
\text { médio dos canais } \\
\text { de cada ordem }\end{array}$ & $R L m=\frac{L m d}{N m u}$ & $\begin{array}{l}\text { Lmd: } \\
\text { comprimento } \\
\text { dos canais; } \\
\text { Nmu: } \\
\text { comprimento } \\
\text { dos canais de } \\
\text { ordem inferior. }\end{array}$ & $\begin{array}{l}\text { A razão entre o } \\
\text { comprimento médio dos } \\
\text { canais de determinada } \\
\text { ordem pelo comprimento } \\
\text { total de canais de ordem } \\
\text { inferior. }\end{array}$ \\
\hline Gcp & Gradiente & $G c p=A m / L p$ & Am: $\quad$ Altitude & Gradiente \\
\hline
\end{tabular}

ENCICLOPÉDIA BIOSFERA, Centro Científico Conhecer - Goiânia, v.13 n.24; p.760 2016 


\begin{tabular}{|c|c|c|c|c|}
\hline & canal principal & & $\begin{array}{l}\text { máxima. } \\
\text { Lp: } \\
\text { Comprimento do } \\
\text { canal principal. }\end{array}$ & $\begin{array}{l}\text { principal indica a relação } \\
\text { entre a cota altimétrica } \\
\text { máxima e o comprimento } \\
\text { do canal principal. }\end{array}$ \\
\hline$D h$ & $\begin{array}{l}\text { Densidade } \\
\text { hidrográfica }\end{array}$ & $D h=\frac{Q c_{b}}{A}$ & $\begin{array}{l}\text { Qcb: número } \\
\text { total de canais } \\
\text { da bacia; } \\
\text { A: área da } \\
\text { bacia. }\end{array}$ & $\begin{array}{l}\text { Relação entre o número } \\
\text { de cursos d'água e a } \\
\text { área de uma dada bacia }\end{array}$ \\
\hline$D d$ & $\begin{array}{l}\text { Densidade } \\
\text { drenagem }\end{array}$ & $D d=\frac{L t}{A}$ & $\begin{array}{l}\text { L: comprimento } \\
\text { total dos canais; } \\
\text { A: área da } \\
\text { bacia. }\end{array}$ & $\begin{array}{l}\text { Relação entre } \\
\text { comprimento total ou } \\
\text { ordem hierárquica dos } \\
\text { canais de drenagem e a } \\
\text { área de drenagem. }\end{array}$ \\
\hline $\mathrm{Cm}$ & $\begin{array}{l}\text { Coeficiente de } \\
\text { manutenção }\end{array}$ & $C m=\frac{1}{D d} \times 1000$ & $\begin{array}{l}\text { Dd: é densidade } \\
\text { de drenagem. }\end{array}$ & $\begin{array}{l}\text { Área necessária para } \\
\text { formação de um canal } \\
\text { com fluxo perene. }\end{array}$ \\
\hline Is & $\begin{array}{l}\text { Sinuosidade do } \\
\text { curso d' água } \\
\text { principal }\end{array}$ & $I s=L p / D v$ & $\begin{array}{l}\text { Lp: comprimento } \\
\text { total dos canais; } \\
\text { Dv: } \\
\text { comprimento } \\
\text { vetorial. }\end{array}$ & $\begin{array}{l}\text { Relação entre } \\
\text { comprimento do rio } \\
\text { principal e a distância } \\
\text { entre a nascente e a foz } \\
\text { em linha reta. }\end{array}$ \\
\hline
\end{tabular}

Fonte: HORTON (1945), VILLELA E MATTOS (1975) E CHRISTOFOLETTI (1981).

\section{RESULTADOS E DISCUSSÃO}

Com base nas informações obtidas em campo, foi possível, por exemplo, observar e avaliar as diferentes características do rio Moju, que integra a bacia bacia do rio Curuá-Una na Floresta Nacional do Tapajós. Na Figura 3, observa-se a ponte sobre - Igarapé do Moju e sua respectiva placa de identificação. Também na Figura 3, apresenta-se os lados esquerdo do Moju, com águas claras, tributário do igarapé do Una cuja foz é no rio Amazonas.
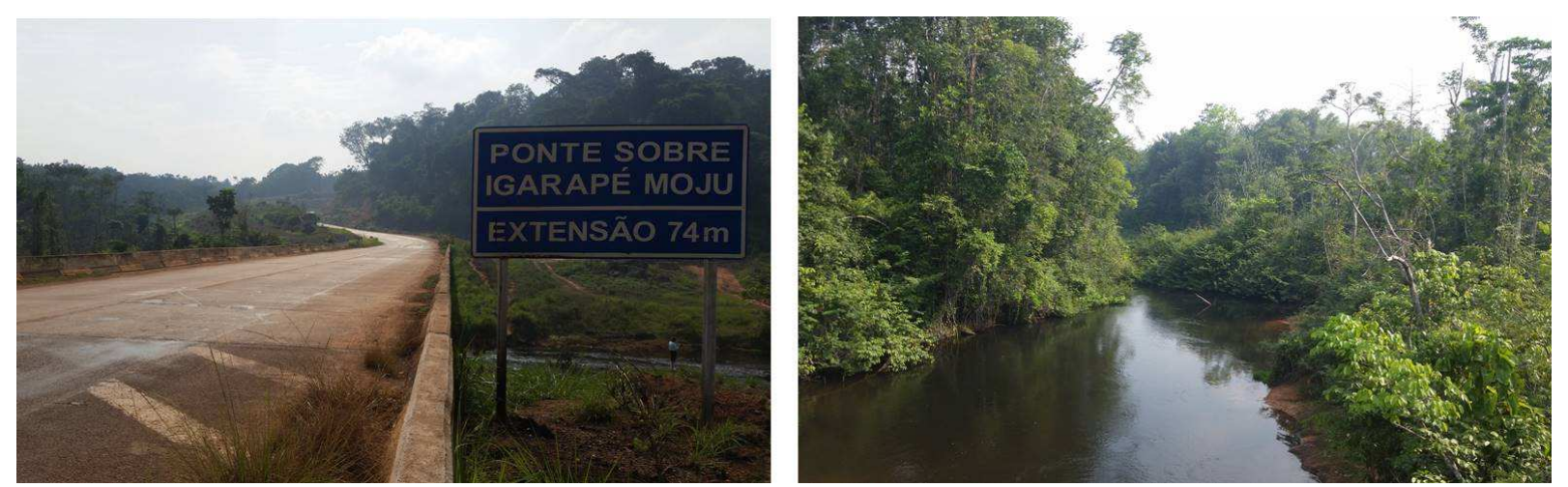

FIGURA 3. Vista da ponte e lado esquerdo do Igarapé Moju na BR-163

Quanto a característica morfométricas a sub-bacia do rio Moju possui uma área de $1.124,95 \mathrm{~km}^{2}$ e perímetro de $376 \mathrm{~km}$, indicando ser uma sub-bacia de grande porte, 
conforme classificação de STRAHLER (1957) E CHRISTOFOLETTI (1981). Identificouse que a SBHRM possui 961 canais de $1^{\text {a }}$ ordem, representando $77 \%$ dos canais. $O$ número de canais de $2^{\mathrm{a}}$ ordem foi de 208 , correspondendo a $16 \%$ da quantidade de canais, seguido de 51 canais de $3^{\text {a }}$ ordem (4\%), 10 canais de $4^{\text {a }}$ ordem $(0,8 \%)$ e 2 canais de $5^{\circ}$ ordem $(0,1 \%)$ e 1 canal de $6^{\text {a }}$ ordem $(0,08 \%)$, de acordo com a classificação automática do TauDEM, totalizando um desdobramento do sistema de drenagem com 1.233 canais. Portanto, evidencia-se que o número de canais no rio Moju diminui conforme o aumento da ordem, correspondendo uma relação inversa entre os números e as ordens dos canais.

Os canais de $1^{\text {a }}$ ordem apresentaram um comprimento total de $836,09 \mathrm{~km}$, os de $2^{\text {a }}$ ordem $337,23 \mathrm{~km}$, os de $3^{\text {a }}$ ordem $186,37 \mathrm{~km}$, os de $4^{\text {a }}$ ordem $827,64 \mathrm{~km}$, os de $5^{\text {a }}$ ordem 500,64 km e por fim o de $6^{\text {a }}$ ordem com 219,90 km. Observou-se através da hierarquia fluvial que há quatro canais de $1^{\underline{a}}$ ordem para cada canal de $2^{\underline{a}}$ ordem, repetindo-se este mesmo valor na passagem dos canais de $2^{\underline{a}}$ ordem para os de $3^{\text {a }}$ ordem. Identificou-se também que os canais de $1^{\text {a }}$ ordem têm em média $209,30 \mathrm{~km}$ e os de $3^{\text {a }}$ ordem $84,30 \mathrm{~km}$. Já na passagem dos canais de $3^{\text {a }}$ ordem para $4^{\text {a }}$, existem 5 canais de $3^{\underline{a}}$ ordem para cada um de $4^{\text {a }}$ ordem, repetindo-se também este valor na passagem dos canais de $4^{\mathrm{a}}$ para o de $5^{\mathrm{a}}$ ordem.

De acordo com a hierarquia dos canais, identificou-se que a SBHRM é de 6 $6^{\text {a }}$ ordem, evidenciando sua alta ramificação, corroborando com os trabalhos que ressaltam que quanto menor a ordem ( $<5$, por exemplo), menos ramificadas são as sub-baciais (FERREIRA et al., 2012; CAMPOS et al., 2015; OLIVEIRA \& ANTÔNIO, 2015). Os valores de comprimento do eixo principal (Lp) e Comprimento total da rede de drenagem (Lt) foram de $82,71 \mathrm{~km}$ e $2.907,87 \mathrm{~km}$, respectivamente. Outros resultados das características morfométricas da sub-bacia são apresentados na Tabela 1.

TABELA 1. Características morfométricas da sub-bacia hidrográfica do rio Moju, PA.

\begin{tabular}{|c|c|c|c|}
\hline \multirow{12}{*}{ Aspectos lineares } & Característica morfométrica & Unidade & Valor \\
\hline & Perímetro da bacia & $\mathrm{km}$ & 376,14 \\
\hline & Coeficiente de manutenção $(\mathrm{Cm})$ & $m^{2}$ & 387,59 \\
\hline & Comprimento do eixo principal da bacia (L) & $\mathrm{km}$ & 82,71 \\
\hline & Comprimento máximo dos canais (Lmax) & $\mathrm{km}$ & 62,52 \\
\hline & Comprimento mínimo dos canais (Lmin) & $\mathrm{m}$ & 0,44 \\
\hline & Comprimento total dos canais & $\mathrm{km}$ & $2.907,87$ \\
\hline & Índice de rugosidade & - & 0,52 \\
\hline & Índice de circularidade & - & 0,09 \\
\hline & Mediana dos canais (Lmd) & $\mathrm{m}$ & 807,33 \\
\hline & Número de canais & - & 1.233 \\
\hline & Ordem da bacia & - & $6^{\underline{a}}$ \\
\hline \multirow{5}{*}{ Aspectos areais } & Área da bacia & $\mathrm{km}^{2}$ & $1.124,95$ \\
\hline & Coeficiente de compacidade (Kc) & - & 1,57 \\
\hline & Densidade de drenagem & $\mathrm{Km} / \mathrm{km}^{2}$ & 2,58 \\
\hline & Densidade hidrográfica & - & 1,09 \\
\hline & Fator de Forma (kf) & - & 0,16 \\
\hline
\end{tabular}


O comprimento médio da relação de bifurcação da SBHRM é de 4,16, representando que em média um canal de ordem superior recebe a contribuição de no mínimo quatro canais de ordem inferior. Quanto ao Coeficiente de compacidade (Kc) e o fator de Forma (Kf) da bacia do rio Moju foram 1,57 e 0,16 respectivamente. Assim, como o $\mathrm{Kc}>1,50 \mathrm{e} \mathrm{Kf}<0,50$ identificou-se que a SBHRM não sujeita a enchentes ou acúmulo de água condições normais de precipitação (VILLELA \& MATTOS, 1975). Em SANTOS et al. (2012) os resultado do $\mathrm{Kc}$ e Kf, para sub-bacia Perdizes, foram semelhantes indicando que esta sub-bacia, em condições normais de precipitação também é pouco suscetíveis a enchentes.

$\mathrm{O}$ resultado dos índices de Kc e Kf é reforçado pelo índice de circularidade (IC) encontrado, ( $I C=0,09)$, indicando que a SBHRM não tendem à forma circular, ou seja, possuem forma mais alongada (VILLELA \& MATTOS, 1975). A Densidade de drenagem (Dd) foi de $2,58 \mathrm{~km} / \mathrm{km}^{2}$ e de acordo com VILLELA \& MATOS (1975) a SBHRM é uma sub-bacia com um rede de drenagem muito boa, visto que este valor está entre 2,5 $\mathrm{Dd}<3,5 \mathrm{~km} / \mathrm{km}^{2}$. De acordo com Coeficiente de manutenção $(\mathrm{Cm})$ encontrado $(\mathrm{Cm}=$ $387,59 \mathrm{~m}^{2}$ ) observa-se que o rio Moju necessita de no mínimo $380 \mathrm{~m}^{2}$ de área de recarga para manter perene um metro de canal de drenagem. Observou-se valores semelhantes deste parâmetros em PEREIRA (2015), na bacia hidrográfica do Rio Peixe Boi, Nordete Paraense. Na Figura 3, de forma geral observa-se que a bacia possui um sistema de drenagem com ramificação significativa de natureza dendrítica, pois lembra a configuração de uma árvore (CHRISTOFOLETTI, 1978). Na Figura 3a, ilustra-se a forma alongada da SBHRM. Na Figura 3b observa-se a distribuição hierárquica dos canais da SBHRM que tem uma Relação de bifurcação $(R b)$ média de 4 canais. Também destaca-se Na Figura 3b a 6⿳亠丷厂 ordem da SBHRM, sendo considerada médio a grande porte, conforme destaca PÉRICO et al. (2011) e COELHO (2007).
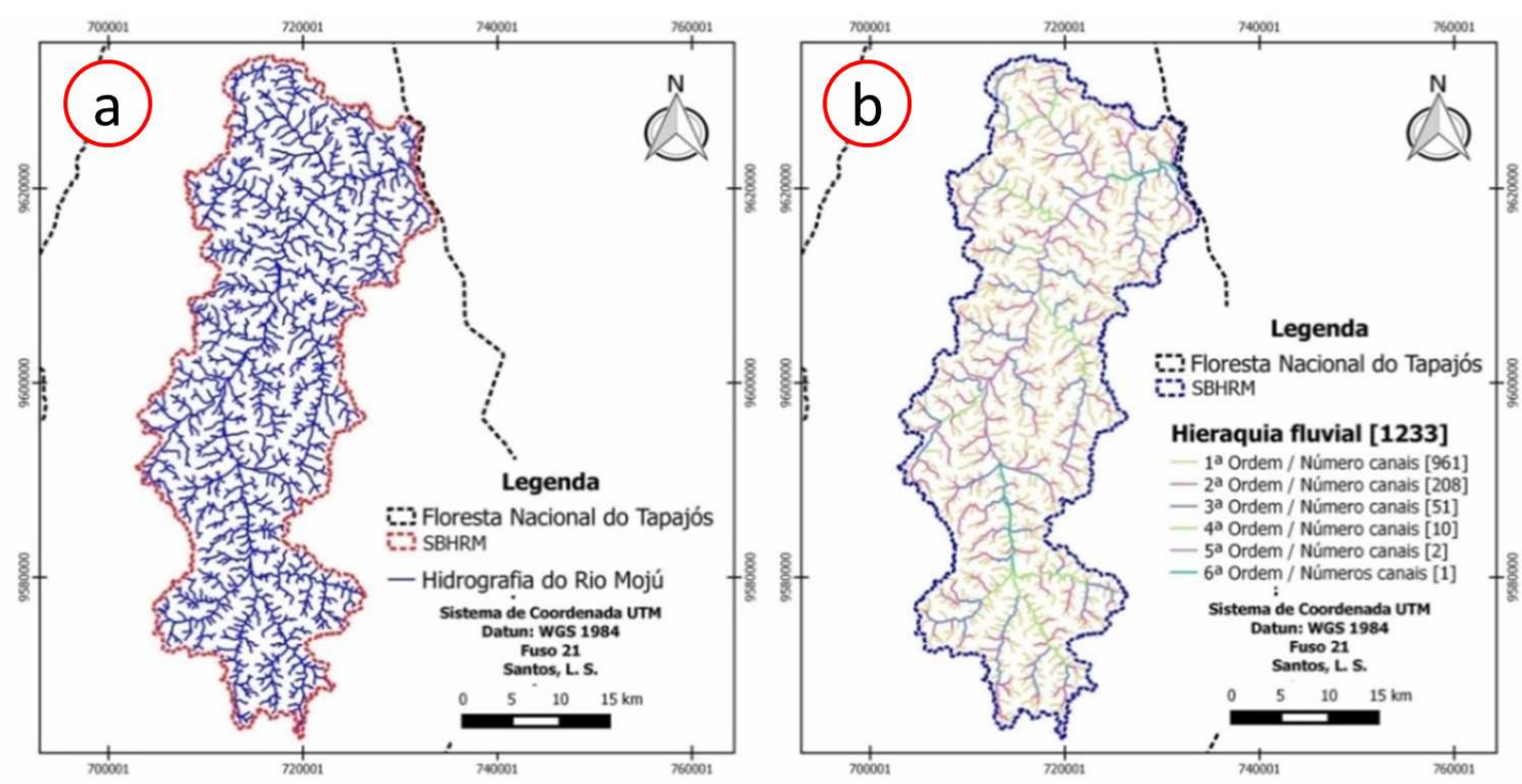

FIGURA 3. Sistema de drenagem e hierarquia fluvial da sub-bacia do rio Moju, PA. 
Pela análise na Tabela 2, observa-se os resultados da Rb da SBHRM que variou de 2 a 5,1, o que representa que cada canal de ordem superior recebe em média a contribuição de 4 canais de ordem inferior, conforme STRAHLER (1952). Com a relação do comprimento médio dos canais $(\mathrm{R} / \mathrm{m})$ de cada ordem concluiu-se que há uma baixa correlação do crescimento da ordem e o comprimento médio dos cursos d'água. Esse resultado forma semelhantes no trabalho de VEIGA et al. (2013).

TABELA 2. Relação de bifurcação (Rb) e comprimento médio dos cursos d'água (RIm) de cada ordem da sub-bacia hidrográfica do rio Moju, PA.

\begin{tabular}{c|c|c|c|c|c|c}
\hline Ordem & Média $(\mathbf{k m})$ & Quantidades & $\mathbf{R b}$ & $\mathbf{\%}$ & $\mathbf{k m}$ & $\mathbf{R I m}$ \\
\hline 1 & 0,870 & 961 & 4,6 & 77,93 & 836,09 & - \\
\hline 2 & 1,62 & 208 & 4,0 & 16,89 & 337,23 & $\mathbf{0 , 4 0}$ \\
\hline 3 & 3,65 & 51 & 5,1 & 4,13 & 186,37 & $\mathbf{0 , 5 5}$ \\
\hline 4 & 8,27 & 10 & 5 & 0,81 & 827,64 & $\mathbf{4 , 4 4}$ \\
\hline 5 & 25,03 & 2 & 2 & 0,16 & 500,64 & $\mathbf{0 , 6 0}$ \\
\hline 6 & 21,99 & 1 & - & 0,08 & 219,90 & $\mathbf{0 , 4 4}$ \\
\hline Total & $\mathbf{6 1 , 4 6}$ & $\mathbf{1 2 3 3}$ & & $\mathbf{1 0 0}$ & $\mathbf{2 9 0 7 , 8 7}$ & - \\
\hline
\end{tabular}

Ao avaliar as classes pluviais (Figura 4a), observa-se que as áreas mais chuvosas ocorrem ao sul da sub-bacia do rio Moju, totalizando nesta área em média $2.170 \mathrm{~mm}$ ao ano decrescendo progressivamente na direção norte. A faixa de maior precipitação ao sul da SBHRM sofre interceptação pela vegetação que posteriormente gera o escoamento superficial sobre a superfície dessa sub-bacia, facilitando a infiltração da água no solo e a recarga da rede de drenagem local e dos aquíferos subterrâneos, transformando-se, finalmente, em vazão do rio Moju (PINTO et al., 1976).

Quanto ao fator de alagamento (Figura 4b), verificou-se que apenas $0,01 \%$ da $\operatorname{SBHRM}\left(0,1 \mathrm{~km}^{2}\right)$ apresentam alta probabilidade de alagamento, 9,67\% $\left(108,74 \mathrm{~km}^{2}\right)$ média probabilidade de alagamento, $54,56 \%\left(613,74 \mathrm{~km}^{2}\right)$ baixa probabilidade de alagamento e $35,77 \%\left(402,38 \mathrm{~km}^{2}\right)$ muito baixa probabilidade alagamento.

A Figura 5 a ilustra o fator de declividade da SBHRM que possui mais de $53,02 \%$ do seu território do tipo relevo ondulado, seguido de $22,56 \%$ como forte ondulado, de $19,43 \%$ com suave ondulado, de $4,08 \%$ com relevo plano e apenas $0,9 \%$ de relevo montanhoso. Na Figura 5b observa-se o fator de orientação de exposição solar da SBHRM que possui $39,3 \%$ de sua área com elevada iluminação solar, seguido de $37,55 \%$ com baixa iluminação solar e $22,78 \%$ com média iluminação solar.

Sabe-se que o relevo e exposição do terreno ao sol é algo mais complexo do que a simples diferença de altitude e orientação entre locais distintos, contudo os resultados descritos representam variáveis que podem auxiliar no planejamento estratégico vinculado à gestão e manejo da SBHRM, permitindo com isso viabilizar a manutenção dos ecossistemas e sua biodiversidade. Por fim, identificou-se que a amplitude altimétrica da SBHRM é de $226 \mathrm{~m}$, com altimetria mínima de $69 \mathrm{~m}$ e a máxima $295 \mathrm{~m}$. 

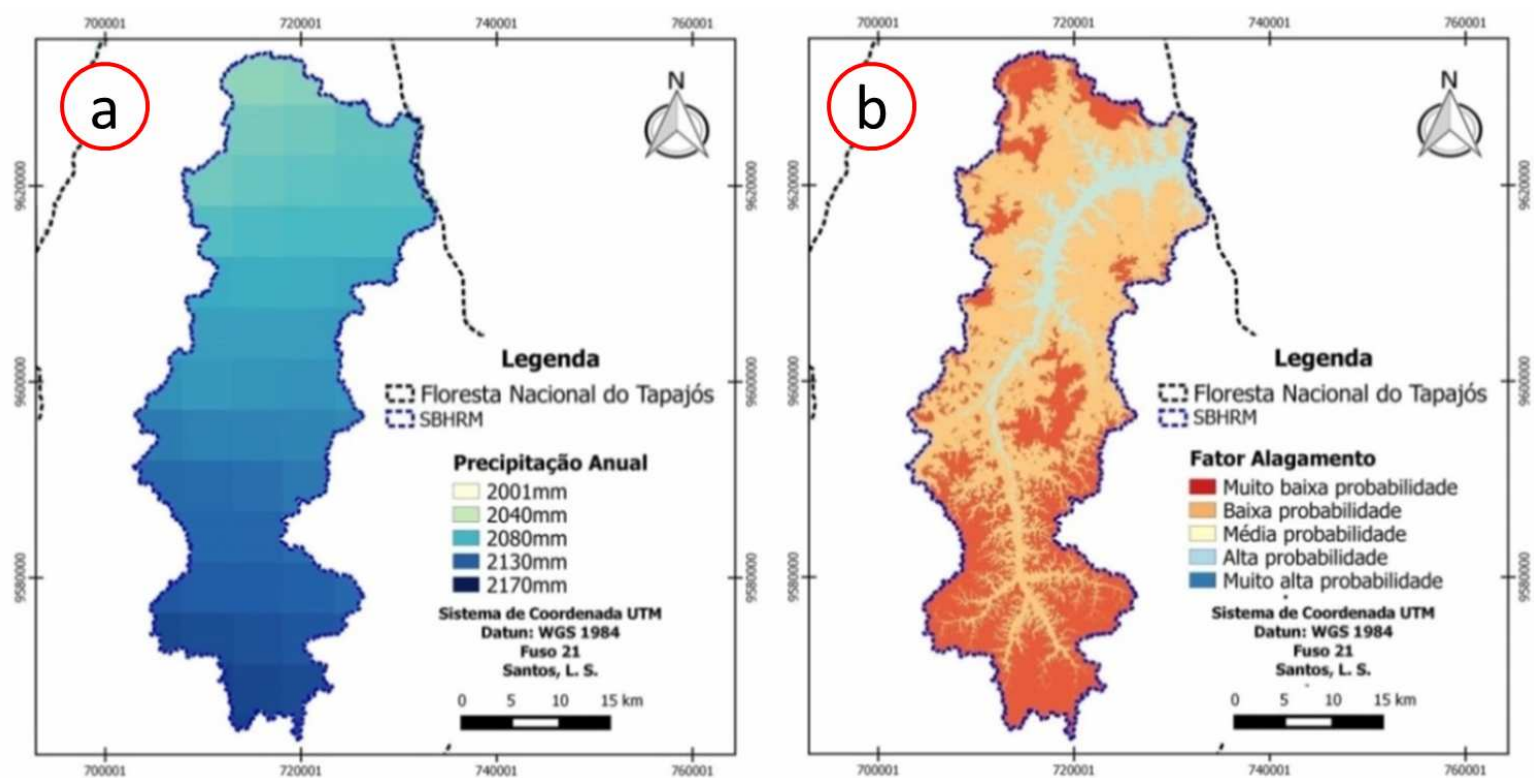

FIGURA 4. Mapa de precipitação anual e probabilidade de alagamento da sub-bacia do Rio Moju.

Com base nas informações obtidas em campo, observaram-se as diferentes características do rio Moju. Neste sentido, sugere-se que haja uma especial atenção para que sejam sempre mantidas preservadas as vertentes da SBHRM, com práticas conservacionistas para manutenção dos cursos d'água. Os resultados apontam que em razão de sua magnitude, a SBHRM é sensível a impactos antrópicos na paisagem, despertando a importância e a necessidade de estudos e pesquisas para subsidiar avaliações dos fatores que ameaçam a manutenção dos corpos hídricos na área em estudo.
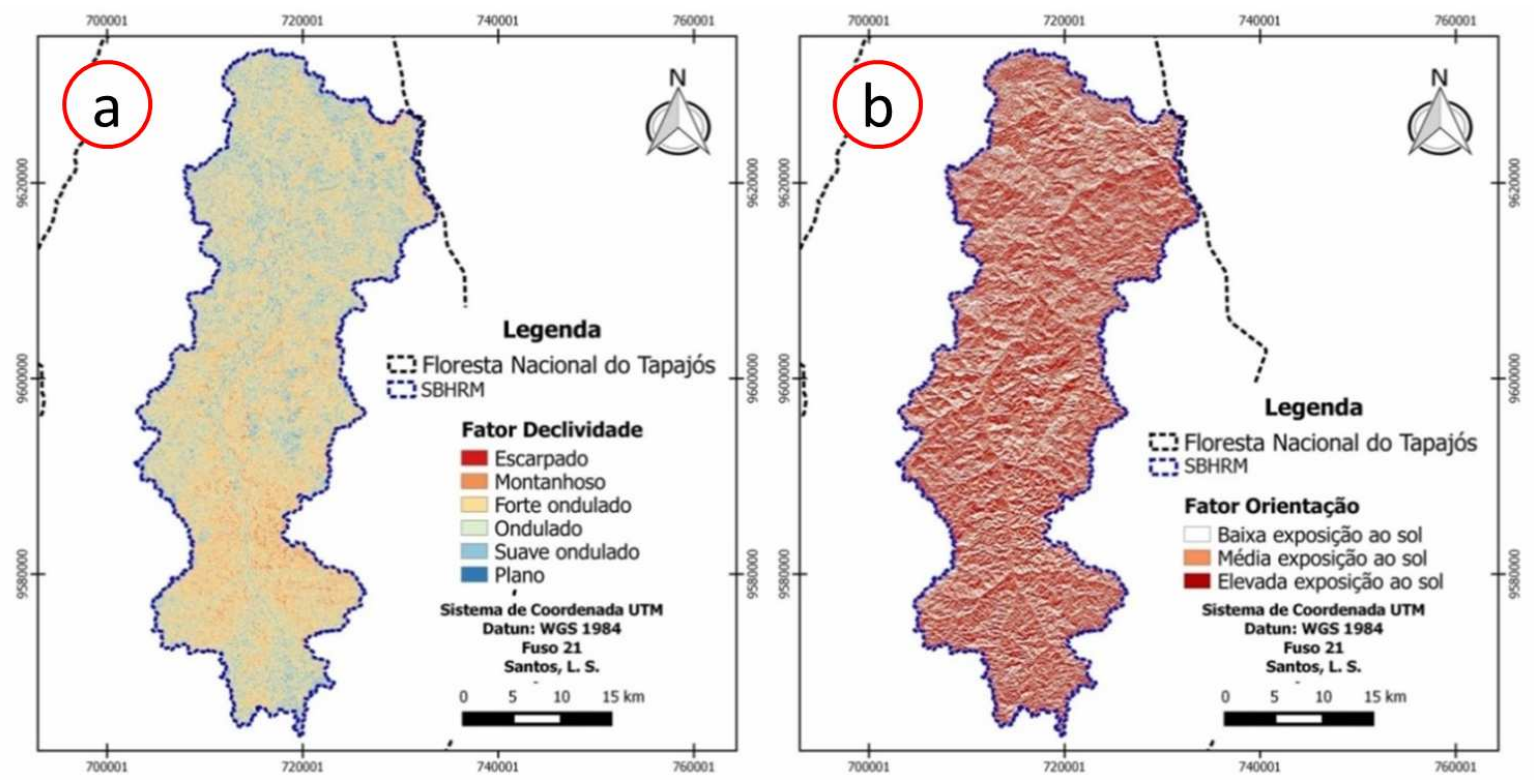

FIGURA 5. Mapa de declividade e exposição solar do terreno na sub-bacia do rio Moju. 
Praticamente, metade das áreas da SBHRM apresenta face do terreno no orientadas no sentido norte e oeste, indicando que se houver perda da cobertura vegetal a reposição de água pela chuva e a saída de água por evaporação e evapotranspiração serão intensificadas ameaçando o processo de armazenamento de água na bacia hidrográfica (FERREIRA et al., 2012).

\section{CONCLUSÃO}

A sub-bacia do rio Moju é uma bacia de forma mais alongada, sendo comprovado pelo índice de circularidade, coeficiente de compacidade e fator de forma. É uma sub-bacia de sexta ordem, sendo a rede de drenagem densamente ramificada com baixa probabilidade de alagamento em razão da predominância do relevo ondulado.

FLONA Tapajós e seu entorno são responsáveis pela manutenção da SBHRM, neste sentido, sugere-se que haja uma especial atenção para que sejam sempre mantidas preservadas a vegetação primária do entrono da SBHRM, com práticas conservacionistas para manutenção dos seus cursos d'água, pois em razão de sua magnitude, a SBHRM é sensível a impactos antrópicos. Desta forma, evidencia-se a importância e a necessidade de estudos e pesquisas sobre a perda de cobertura vegetal que induz a intensificação de perdas de solo, água, material orgânica e nutrientes nesta área, principalmente ao logo do rio Moju. Assim a perda da vegetação primária pode gerar impactos ameaçando a manutenção dos corpos d'água, principalmente na área de entorno que possui extensas área ocupadas por agricultura anual e pastos.

Assim, o entendimento de características morfométricas variáveis da SBHRM devem ser utilizados no planejamento, proteção e conservação ambiental desse recurso hídrico na FLONA do Tapajós e seu entorno. Por fim, os resultado deste trabalho podem subsidiar o gerenciamento e outorgas de água, canais prioritários para abastecimento hídrico e principais vias de contaminação de água pelo processo antrópico na SBHRM e ainda facilitar o processo de tomada de decisão quanto à definição de áreas prioritárias para o desenvolvimento de pesquisas e ações quanto a Política Nacional de Recursos Hídricos, tendo como foco o uso conservacionista da água na Amazônia.

\section{AGRADECIMENTOS}

Ao Programa de Pós-Graduação em Ciências Ambientais, em nível de mestrado acadêmico, ofertado pela Universidade do Estado do Pará (UEPA), na cidade de Belém-PA; ao Núcleo de Apoio à Pesquisa no Pará (NAPPA) do Instituto Nacional de Pesquisas da Amazônia (INPA), em Santarém-PA, pelo apoio logístico nas atividades de campo; ao escritório do Instituto Chico Mendes de Conservação da Biodiversidade (ICMBio), na cidade de Santarém-PA, pelo apoio técnico. Os autores registam também seus agradecimentos a Embrapa Amazônia Oriental pela oportunidade de realização deste trabalho em âmbito do Projeto ROBIN (Role Of Biodiversity In climate change mitigation). 


\section{REFERÊNCIAS}

BIELENKI JÚNIOR, C; ARBASSA, A. P. Geoprocessamento e recursos hídricos: aplicações práticas. $1^{1}$ ed. São Paulo: EDUFSCAR, 2012.

BOSSLE, R. C. QGis e Geoprocessamento na Prática. $1^{\underline{a}}$ ed. Vol. I. São José dos Pinhais: Íthala, 2015.

CAMPOS, S.; UZÓ, M.; CAMPOS, M.; PISSARA, T. C. T.; RODRIGUES, B. T.. Caracterização morfométrica da microbacia do rio Bauru/SP obtida por técnicas de geoprocessamento. InterEspaço: Revista Brasileira de Geografia e Interdisciplinaridade, p. 222-234, Ed. Especial: 2015. Disponível em:< http://dx.doi.org/10.18766/2446-6549/interespaco>. Acesso em: 30 jun. 2016.

CHRISTOFOLETTI, A. A morfologia de bacias de drenagem. Notícias Geomorfológicas. v.18, n. 36. p. 130-142, 1978.

CHRISTOFOLETTI, A. A variabilidade espacial e temporal da densidade de drenagem. Notícias Geomorfológicas. v. 21, p. 3-22, 1981.

COELHO, A. L. N. Aplicações de Geoprocessamento em Bacias de Médio e Grande Porte. Anais do XIII Simpósio Brasileiro de Sensoriamento Remoto, Florianópolis, Brasil, 2437-2445, 2007. Disponível em:< http://marte.sid.inpe.br/col/dpi.inpe.br/sbsr@80/2006/10.31.17.41/doc/2437-2445.pdf >. Acesso e, 13 out. 2016.

FERREIRA, R. G.; MOURA, M. C. O.; CASTRO, F. S. Caracterização morfométrica da sub-bacia do Ribeirão Panquinhas, ES. Revista Enciclopédia Biosfera, Goiânia, v. 8, n. 15 p. 2250-2256, 2012. Disponível em: < http://www.conhecer.org.br/enciclop/2012b/engenharias/caracterizacao\%20morfometric a.pdf>. Acesso em 25 jul. 2016.

FERREIRA, E. P.; FERREIRA, J. T. P.; PANTALEÃO, F.; FERREIRA, Y. Desafios para a gestão da bacia hidrográfica do Rio Mundaú-Diagnóstico ambiental de trechos da bacia localizada no estado de alagoas. Revista Enciclopédia Biosfera, v. 8, p. sn, 2012.

Disponível em:<http://www.conhecer.org.br/enciclop/2012a/ambientais/desafios.pdf>. Acesso em 14 out. 2016.

HORTON, R. E. Erosinal development of streams and their drainage basin: Hydrophysical approach to quantitative morphology. Geological Society of America Bulletin. v. 56, p. 275-370, 1945.

JENSEN, J. R. Sensoriamento remoto do ambiente: uma perspectiva em recursos terrestres. $2^{\underline{a}}$ ed., Instituto Nacional de Pesquisas Espaciais - INPE (trad.). São Paulo: Parêntese, 2009. 
OLIVEIRA, B. R.; ANTÔNIO, G. B. Caracterização da bacia do Maxixe com o auxílio de Sistemas de Informações Geográficas. Revista Eletrônica em Gestão, Educação e Tecnologia Ambiental, v. 19, n. 3, p. 761-782, set-dez, 2015. Disponível em:<http://dx.doi.org/10.5902/2236117018933>. Acesso em 15 ago. 2016.

OLIVEIRA, L. B.; AZEVEDO, J. M. A.; AMARAL. A. L.; FERRARI. J. Caracterização morfométrica da Sub-bacia hidrográfica do Ribeirão São Bartolomeu. Revista Enciclopédia Biosfera, Goiânia, v. 11, n. 22, p. 72-82, 17 dez, 2015. Disponível em:< http://www.conhecer.org.br/enciclop/2015E/caracterizacao\%20morfometrica.pdf>. Acesso e, 20 ago. 2016.

OLIVEIRA, P. T. S.; SOBRINHO, T. A.; STEFFEN, J. L.; RODRIGUES, D. B. B. Caracterização morfométrica de bacias hidrográficas através de dados SRTM. Revista Brasileira de Engenharia Agrícola e Ambiental, v. 14, n. 8. Campina Grande, 2010. Disponívelem:<http://dx.doi.org/10.1590/S1415-43662010000800005>. Acesso em: 12 jul. 2016.

PEREIRA, B., MACIEL, M., OLIVEIRA, F., FERREIRA, B., \& RIBEIRO, E. Geotecnologias com apoio de índices morfométricos para a caracterização da bacia hidrográfica do rio Peixe-Boi, Nordeste Paraense. Revista Enciclopédia Biosfera, v. 12, n. 22, p. 2960-2974, 2015. Disponível em: DOI: http://dx.doi.org/10.18677/Enciclopedia_Biosfera_2015_165. Acesso em 12 mai. 2016.

PÉRICO, E.; CEMIN, G.; AREND, Ú.; REMPEL, C. Análise fisiográfica da bacia hidrográfica do rio Forqueta, RS, 2011. Anais XV Simpósio Brasileiro de Sensoriamento Remoto - SBSR, Curitiba, PR, Brasil, 30 de abril a 05 de maio de 2011, INPE p.1200. Disponível em:

http://marte.sid.inpe.br/col/dpi.inpe.br/marte/2011/07.15.19.02/doc/p0911.pdf>. Acesso em: 13 out. 2016 .

PINTO, N. L; HOLTZ, A. C. T.; MARTINS, J. A., GOMIDE, F. L. S. Hidrologia Básica. São Paulo. Edgard Blücher, 1976.

RIBEIRO, E. G.; FERREIRA, B. M.; N., MACIEL. M.; PEREIRA, B. W.; SOARES, J. A. Caracterização morfométrica da bacia hidrográfica do Igarapé do Una por meio de geotecnologias. Revista Enciclopédia Biosfera, Goiânia, v. 11, n. 21, p. 2960-2974, jun., $2015 . \quad$ Disponível em:< http://www.conhecer.org.br/enciclop/2015b/multidisciplinar/caracterizacao\%20morfometr ica.pdf >. Acesso em 15 jul. 2016

SALES, V. C. Geografia, sistemas e análise ambiental: Abordagem crítica. GEOUSP Espaço e Tempo, São Paulo, n. 16, p. 125 - 141, 2004.

SANTOS, A. M.; TARGA, M. S.; BATISTA, G. T.; DIAS, N. W. Análise morfométrica das sub-bacias hidrográficas Perdizes e Fojo no município de Campos do Jordão, SP, 
Brasil. Revista Ambi-Agua, Taubaté, v. 7, n. 3, p. 195-211, 2012. Disponível em:<http://dx.doi.org/10.4136/ambi-agua.945>. Acesso em 14 out. 2016.

SANTOS, L. S.; GUTIERREZ, C. B.; PONTES, A. N.; SILVA JUNIOR, O. M.; SOUZA, A. A.; MARTORANO, L. G. Geotecnologia aplicada na análise de bacias hidrográficas e rede de drenagem: Estudo das bacias hidrográficas do Murucutu e Aurá. Revista SODEBRAS. v. 11, n. 124, p. 131-135, abr., 2016. Disponível em: < http://www.sodebras.com.br/edicoes/N124.pdf >. Acesso em: 23 jun. 2016.

STIPP, N. A.; CAMPOS, R. A.; CAVIGLIONE, J. H. Análise morfométrica da bacia hidrográfica do rio Taquara - uma contribuição para o estudo das ciências ambientais. Portal de Cartografia: GEOCIÊNCIAS, v. 3, n. 1, p. 105-124, 2010. Disponível em:< http://www.uel.br/revistas/uel/index.php/portalcartografia/article/view/8929/7451>. Acesso em 22 jul. 2016.

STRAHLER, A. N. Hypsometric (area-altitude) analysis of erosional topography. Geological Society of America Bulletin, v. 63, n. 11, p. 1117-1142, 1952. Disponível em:<doi: 10.1130/0016-7606(1952)63[1117:HAAOET]2.0.CO;2>. Acesso em 22 jul. 2016.

STRAHLER, A. N. Quantitative analysis of watershed geomorphology. Transactions: American Geophysical Union, v. 38, p. 913-920, 1957. Disponnível em:< http://onlinelibrary.wiley.com/doi/10.1029/TR038i006p00913/full>. Acesso em 5 mai. 2016.

TOMAZONI, J. C.; GUIMARÃES, E.; GOMES, T. C.; SILVA, T. G. Uso de modelo digital de elevação gerados a partir do ASTER GDEM e SRTM para caracterização de rede de drenagem. Revista Brasileira de Geografia Física, Recife, v. 4, n. 2, p. 365-376, 2011. Disponível em: <http://www.revista.ufpe.br/rbgfe/index.php/revista/article/view/184/170>. Acesso em: 17 jun. 2016.

VEIGA, A. M.; TRINDADE, M. C.; SOUZA, R. M.; OLIVEIRA, W. NUNES. Caracterização hidromorfológica da bacia hidrográfica do rio Dos Bois. Anais do XX Simpósio Brasileiro de Recursos Hídricos, 2013. Disponível em : < http://www.cprm.gov.br/publique/media/Evento_Veiga_Carac.pdf >. Acesso em 13 out. 2016.

VILLELA, S. M.; MATTOS, A. Hidrologia aplicada. $1^{\text {a }}$ ed., São Paulo: McGraw-Hill, 1975. 